\title{
Memória
}

\section{Adolpho Ducke: Uma visão de conservação da Amazônia}

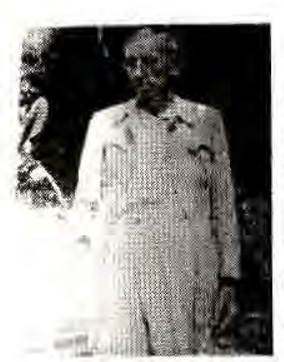

\author{
Ires Paula de Andrade MIRANDA*
}

O naturalista Adolpho Ducke, nascido em 27 de outubro de $1876 \mathrm{em}$ Trieste, Italia, foi um dos botânicos que mais contribuiram para a identificação $\mathrm{e}$ catalogação de espécies, e para o estudo da biogeografia da floresta amazônica. Foi contratado pelo Museu Paraense Emílio Goeldi em 15 de julho de 1899, aos 23 anos de idade, como técnico da seção de Zoologia. Na primeira expedição efetuada a Mazagão (atual Território Federal do Amapá) em 1900, já fazia parte, de suas coletas entomológicas alguns exemplares de plantas coletados por determinação do eminente botânico Jacques Huber, entấo diretor do Museu.

Em sua publicação de 1909, Jacques Huber diz: "De alguns anos para cá o Sr, A. Ducke, entomologista do Museu Goeldi, aproveitou as suas viagens ao interior deste Estado, feitas em comissão deste estabelecimento, para colecionar, além de insetos, um bom número de plantas sêcas". A partir de 1914 influenciado por Jacques Huber iniciou a coleta sistemática de espécimes botânicos, e em 1918, assumiu a chefia da seção de Botânica do Jardim Butânico do Rio de Janeiro.

Ducke foi essencialmente um pesquisador de campo, deixando cerca de 180 publicações, descrevendo mais de 900 espécies botânicas novas. Dentre os trabalhos realizados no periodo de 1900 a 1959 destacamse: Notas sobre o clima da Amazônia (1911); Diversidade dos guaranás (1937); A Amazônia brasileira (1939); As leguminosas da Amazônia brasileira (1939); O cumarú (Dipteryx) na botånica sistemática e geográfica (1939); Notas sobre a fitogeografia da Amazônia brasileira (1954). Este último constituiu uma tentativa de fixar os limites da floresta amazônica e definir as diferenças floristicas existentes na parte brasileira a partir da distribuição do gênero Hevea.

A partir de uma expedição realizada entre maio de 1927 a abril de 1930, as atenções de Ducke e outros pesquisadores voltaram-se para o alto Amazonas e principalmente para o rio Negro, onde, segundo ele, "a flora hileana atinge o climax no número de gêneros, espécies e endemismos". Durante o tempo que o pesquisador esteve no Museu Paraense Emilio Goeldi, suas coletas concentraram-se no baixo Amazonas, nas regiōes de Óbidos, Faro e baixo Tapajós. Com interesse voltado à flora do alto Amazonas, surge a necessidade de que a sede dos serviços fosse estabelecida não mais em Belém e sim em Manaus, para onde Ducke, a partir de 1933, se deslocava do Rio de Janeiro.

Durante suas expedições cientificas, Adolpho Ducke contribuiu sobremaneira com o acervo do Herbário do INPA, introduzindo 76 tipos nomenclaturais de Fanerógamas novas para a ciência, além de vários outros exemplares.

Em homenagem a Adolpho Ducke, João Geraldo Kuhlmann descreveu em 1925 o gènero monotípico Duckeodendron (Solanaceae), endêmico da Amazônia central. Com base em informações adicionais de caracteristica do fruto e embriâo, mais tarde, Kuhlmann criou uma nova familia: Duckeodendraceae.

$\mathrm{Na}$ década de 50, Ducke sugeriu, junto com outros botânicos, a preservação de uma região próxima à Manaus devido à grande diversidade florística observada. Em 1956 aquela área tornou-se o Centro de Pesquisas Florestais do INPA. Em 1962, o Centro com 10.000 hectares foi doado ao INPA, rercebendo o nome de Reserva Florestal Adolpho Ducke, situada hoje no $\mathrm{km} 26$ da rodovia AM 010.

Adolpho Ducke faleceu em 05 de janeiro de 1959, em Fortaleza, Ceará.

\footnotetext{
- Coordenação de Pesquisas em Botânica - INPA. Av. André Araújo, 1756 - C.P. 478 Manaus, AM 69083-000
} 